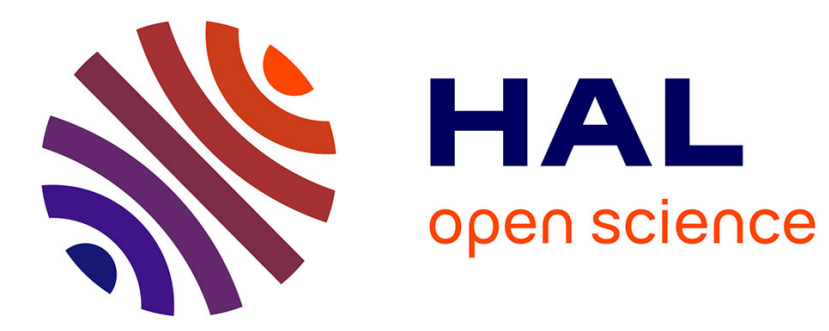

\title{
Imagination, Desire, and Irrationality: A Defense of i-desire Account
}

Yuchen Guo

\section{To cite this version:}

Yuchen Guo. Imagination, Desire, and Irrationality: A Defense of i-desire Account. International Journal of Philosophical Studies, 2020, pp.1-13. 10.1080/09672559.2020.1851283 . hal-03104659

\section{HAL Id: hal-03104659 \\ https://hal.sorbonne-universite.fr/hal-03104659}

Submitted on 9 Jan 2021

HAL is a multi-disciplinary open access archive for the deposit and dissemination of scientific research documents, whether they are published or not. The documents may come from teaching and research institutions in France or abroad, or from public or private research centers.
L'archive ouverte pluridisciplinaire HAL, est destinée au dépôt et à la diffusion de documents scientifiques de niveau recherche, publiés ou non, émanant des établissements d'enseignement et de recherche français ou étrangers, des laboratoires publics ou privés. 


\section{IMAGINATION, DESIRE, AND IRRATIONALITY: A defense of i-desire account}

We often have all kinds of affective responses to fictional events and characters. Conventionally, there are three competing theories to account for our affective responses to fictional events. ${ }^{1}$ Spaulding (2015) call them, respectively, imagination + i-desire, imagination + desire, and desire + desire. $^{2}$ The imagination $+i$-desire account is an explanation parallel to our affective responses to real events. In real life, the combination of our beliefs and our desires can generate our affective responses. Suppose that your friend encounters a lion on the wild plains of South Africa. The event causes you anxiety. It seems that you have a belief that the lion is dangerous and a desire that it not attack your friend. If you lack either this belief or this desire, you would not feel anxiety. Just as beliefs and desires generate our affective responses to real events, the proponents of the imagination + $i$-desire account propose that the combination of imagination and i-desires, as imaginative analogues of beliefs and desires, generates our affective responses to fictional events. For example, when we watch Romeo and Juliet, we imagine that Romeo is dead and have an i-

$1 \quad$ I use the term "affective response" rather than "emotional response." The former is more appropriate for describing our engagement with fiction because of the theoretical position that holds that we do not have real emotions toward fictional events but quasi-emotions or i-emotions (see Walton 1990). Quasi-emotions differ from real emotions as regards their cognitive origin (quasi-motions are not generated by existence beliefs) and their behavioral consequences (quasi-emotions are not motivational). For example, I fear Godzilla; but I do not believe there exists a real Godzilla that is horrible, and I am not motivated by my fear to run away. Hence, this is a "quasi-fear". Though quasi-emotions are not real emotions, they are phenomenologically similar-both can be seen as a kind of affective response. I do not distinguish quasi-emotions and real emotions. When I mention "fear," "pity," or other terms relating to emotion, they refer to either real emotions or to quasi-emotions.

2 It should also be noted that not all affective responses can be interpreted by the three theories. Sometimes, our affective responses do not necessitate a desire-like component. For instance, a ghost suddenly appearing on the screen makes you scared; you do not need any desire to cause your fear. The three theories account for only those "high-level" emotional experiences requiring cognitive and conative components. 
desire that Romeo not die. The combination of this imagining and this i-desire causes our affective responses.

What is an i-desire? Given that our imaginings can mirror the inferential role of beliefs, share mind-to-world direction of fit, and generate emotional states, philosophers agree that imaginings can be seen as a distinctive cognitive attitude and that they can be belief-like (see Currie \& Ravenscroft 2002; Nichols 2004a; Walton 1990). If human imagining can take a belief-like form, then there may be an imaginative analogue of desire. Recently, several philosophers have argued that imaginings can also be seen as a distinctive conative attitude. ${ }^{3}$ These imaginative analogues of desire are referred to as i-desires.

There are two alternative theories: imagination + desire and desire + desire. According to the desire + desire account, we have two conflicting desires concerning the fiction. We desire that the fiction be such that an event occurs, but also desire that the fiction be such that the event not occur. For example, we desire that Othello be such that Desdemona dies, but we also desire that the play be such that Desdemona does not die. The two conflicting desires cause our negative affective responses to the fictional events.

According to the imagination + desire account, we imagine that such an event $E$ occurs and also desire that $E$ not occur. It should be noted that the desire being invoked in this account is neither a desire concerning the fiction nor an imaginative desire, but a real desire concerning fictional events or characters. For example, we imagine that Desdemona was killed by Othello and genuinely desire that she not die. The combination of this

3 Unlike belief-like imaginings, there is no agreement about whether i-desire is a key component in mental architecture. For arguments for i-desires, see Currie (2010); Doggett \& Egan, (2012); Goldman (2006); Velleman (2000). For a dissenting position, see Funkhouser \& Spaulding (2009); Kind (2011); Salis (2016) and Spaulding (2015). 
imagining and this desire produces our tragic response. ${ }^{4}$

The proponents of $\mathrm{i}$-desire argue that the imagination $+i$-desire account is the best explanation because the alternative accounts imply that consumers of fiction are irrational. However, Spaulding (2015) challenges this claim. She argues that the imagination + desire and desire + desire accounts do not imply that consumers of fiction are irrational because there are no rationality constraints on desires. In this paper, I attempt to rebut Spaulding's arguments. In the next section, I describe Spaulding's arguments against the imagination + $i$-desire account. In Section II, I argue that the proponents of the imagination $+i$-desire account can appeal to two kinds of rational norms that Spaulding has not considered. Thus, the imagination + desire and desire + desire accounts still imply that consumers of fiction are irrational.

\section{SPAULDING'S ARGUMENTS AGAINST THE IMAGINATION + I-DESIRE}

\section{ACCOUNT}

The proponents of the idea of i-desire argue that the imagination $+i$-desire account is the

4 The desire + desire account does not deny that imagination is involved in our engagement with fictions. It only claims that conflicting desires "allegedly explain our affective responses" (Spaulding, 2015, p.11) and that there is no need to "invoke imagination as part of the explanation of our affective responses" (Ibid.). In addition, unlike the imagination + desire account, nobody has attempted to provide a detailed interpretation of how conflicting desires can explain all our negative emotions toward tragedies, such as pity or sadness.

Nichols (2004b, p.332), Weinberg and Meskin (2006, p.234) seem to implicitly advocate a version of the desire + desire account. However, they prefer to use the case of conflicting desires to account for the tension that consumers of fiction experience, rather than the general negative emotions, such as sadness or pity. In consuming the fiction, we often hope that characters do well, while wanting that the fiction is a tragedy; therefore, we experience tension. Nichols, Weinberg and Meskin think that conflicting desires can sufficiently explain the experienced tension. However, they do not mention the relationship between conflicting desires and negative emotions. Hence, it seems that the desire + desire account is not a full-fledged theory. While it can account for why consumers of fiction experience tension, it does not easily explain why consumers also experience negative emotions, such as sadness and pity. Indeed, this might be one reason why Spaulding prefers the imagination + desire account instead of desire + desire. 
best explanation for our affective responses because the alternative accounts, imagination + desire and desire + desire, imply that we are irrational when engaging with fiction; but it is obvious that we are not irrational in those cases in which both account falsely imply we are. Spaulding challenges this argument and argues that there are no plausible norms of rationality according to which the alternative accounts imply that consumers of fiction are irrational. In this section, I describe her arguments against the imagination $+i$-desire account. $^{5}$

To begin with, consider Currie and Doggett and Egan's arguments against the imagination + desire and desire + desire accounts. According to the desire + desire account, in engaging with fictions, we have a desire that the fiction be such that the event $E$ occurs, but also desire that the fiction be such that $E$ does not occur. The two conflicting desires generate our tragic responses. According to Doggett and Egan (2012), while our desire is not satisfied, we are disappointed. Thus, if we have two conflicting desires, the rational response would be always disappointed. For example, we desire that Othello be such that Desdemona die, but we also desire that the play be such that Desdemona does not die. Given that Desdemona dies in the play, we are disappointed because our desire that she not die cannot be satisfied. If Desdemona did not die in the play, we would also be disappointed because we have another desire that she die. In this case, no matter whether Desdemona dies in the play, we would be always disappointed.

Currie (2010) uses a similar argument. While we have two conflicting desires, we are ambivalent. Suppose that I have a desire to smoke and also have a desire to give up smoking

5 Spaulding also argues that the imagination $+i$-desire account itself faces three problems. First, it cannot explain the motivational power of i-desires; second, it lacks the justification for i-desires; third, our mental states are not the imaginative simulation of the mental states of the characters or of the hypothetical observers of facts. In this paper, I do not consider the three problems, but only consider her arguments against the rationality constraint on desires. 
because of health problems. In this case, I should always be hesitant: I do not know whether I should smoke, which is an ambivalent attitude.

It seems that given that we have conflicting desires, our rational responses are disappointment or ambivalence. However, we are not at all disappointed or ambivalent in engaging with fictions. We enjoy the fiction and feel pleasure in reading a novel or watching a movie. Thus, we turn out to be irrational. Some of readers may be irrational in consuming fictions. However, our affective responses are not always irrational. According to Currie and Doggett and Egan, the desire + desire account implies that we are irrational all the time when we engage in fictions. Thus, this view is implausible.

Consider the imagination + desire account. This account implies that we have a desire concerning fictional events or characters. For Doggett and Egan, a desire about a fictional event or character rationally implies a desire about the content of the fiction. The desire that Romeo not die rationally requires that we have a desire that the play be such that Romeo does not commit suicide. We know that the only way for the character to come to have certain properties is to change the content of the fiction. Thus, when we desire that a character come to have certain properties, we should desire that she or he comes to have those properties in the fiction.

This requirement of rationality in relation to desires leads to a dilemma. On the one hand, if we have a desire about fictional events without a desire about the content of the fiction, then we are irrational because we violate the requirement of rationality in relation to desires. On the other hand, if we really have a desire about the content of the fiction, as the desire + desire account introduces, we still have two conflicting desires about the content of the fiction. In this case, the imagination + desire account faces the same problem as the 
desire + desire account.

Nevertheless, Spaulding explains that there are no plausible principles of rationality according to which the imagination + desire and desire + desire accounts imply that consumers of fiction are irrational. She considers four kinds norms of rationality in relation to desire and argues that desire is not constrained by the four norms. First, consider the constraint of logical consistency. Consistency is a rational norm for beliefs. It is inconsistent to believe both $p$ and not- $p$ at the same time. When we come to have a new belief, we revise our current beliefs to make the web of our beliefs consistent. Perhaps rationality also requires that our desires are consistent: we ought to revise our occurrent desires that are not consistent with our new desire. Spaulding claims that there is no such a rationality constraint. We often maintain inconsistent desires. For example, we desire to drink a beer and also desire to remain sober because of health problems; or I desire to smoke and also desire to give up. We recognize that our desires are inconsistent, but we do not reject one of these desires. If we judge that a rational person's desires should be consistent, then we are all irrational. It is obviously implausible to attribute widespread irrationality to people.

Then consider the constraint of inferential coherence. Beliefs are constrained by the rationality of inferential coherence. We should believe what follows from our beliefs. As with beliefs, there may be a rationality constraint on the inferential coherence of desires: we should desire what follows from our other desires. Doggett and Egan's argument against the imagination + desire account explicitly relies on the inferential coherence requirement. They say that a desire about fictional events and characters rationally requires that one has a desire about the content of the fiction: if we have a desire that Desdemona not die, then we ought to desire that she not die in the play. Spaulding argues that the inferential coherence 
requirement is often violated amongst desires. She uses an example: I desire to run early in the morning, but I do not desire to get up early in the morning. In order to run early in the morning, I must get up early. The former requires the latter. However, I desire the former, but not the latter. We have such type of desires all the time. Thus, we are often irrational. Given that attributing widespread irrationality is implausible, Spaulding claims that there is no inferential coherence requirement in relation to desires: rationality does not require that if we have a desire about fictional events, we should have a relevant desire about the content of the fiction.

Next, consider the justification and possibility requirements in relation to desires. Beliefs are thought to be irrational when they are formed without sufficient justification. Similarly, desires are also irrational when they are formed without justification. However, Spaulding rejects this requirement. She claims that beliefs without justification are irrational, because beliefs are supposed to represent the world accurately. If a belief lacks justification, then there is no reason to judge that it represent the world accurately. Hence, a belief without justification is irrational. However, desires are not supposed to accurately represent the world; Desires have a world-to-mind direction of fit. Even if the content of my desire is not an accurate representation of the world, I can have such a desire. For instance, I missed the last train. In this case, I can desire that it comes, although the content of my desire is not justified. Besides, in some cases, we have no idea why we come to desire certain things. Many of our desires are not justified. Therefore, justification is not a rationality constraint on desire.

Maybe it is irrational for one person to believe something impossible. Fictional events are obviously unattainable. Thus, desires concerning fictional events are irrational. 
Spaulding rejects this requirement too. In fact, we often desire something impossible. I can desire that my son be in good health even though I do not have a son; I also can desire that the 2000 U.S. presidential election had turned out differently (Spaulding's example); a cancer patient can desire that she had never suffered from health problems. If it were irrational for one to desire something impossible, then we would be irrational all the time. Given that widespread attributions of irrationality are implausible, possibility is not a rationality constraint on desire.

The proponents of the idea of $\mathrm{i}$-desires argue that the imagination $+i$-desire account is the best explanation for an affective response to fictional events because the alternative accounts imply that consumers of fiction are irrational all the time. Spaulding argues that there is no plausible norms of rationality on desires according to which the alternative accounts imply an irrationality. Therefore, the imagination $+i$-desire account is not the best explanation. ${ }^{6}$ In the next section, I argue that the imagination $+i$-desire account remains the best explanation on rationality of consumers of fiction because there are two kinds of rationality requirements that Spaulding has not considered and the two alternative accounts violate these requirements.

\section{IMAGINATION, DESIRE AND IRRATIONALITY}

Consider again Currie and Doggett and Egan's arguments against the desire + desire account. Currie argues that conflicting desires imply that consumers of fiction are ambivalent; Doggett and Egan argue that conflicting desires imply that consumers of fiction

6 Spaulding's aim is to reject the imagination $+i$-desire account. In fact, she does not provide any direct arguments for the two alternative accounts. She is more inclined to accept the imagination + desire account than the desire + desire account because she believes that the former explains many features of our engagement with fiction (see Spaulding 2015, p.20). 
are disappointed. It should be noted that they do not simply say that if one person has two inconsistent desires then one person is irrational. Rather, they are inclined to say that the conflicting desires imply that consumers of fiction are disappointed or ambivalent all the time when engaging with fictions-yet often we do not feel disappointed or ambivalent; so we are irrational. In other words, what makes us irrational is not the conflicting desires themselves; it is rather the fact that we do not feel those affective states that the conflicting desires generate. Doggett and Egan (2012, p.282) explicitly say:

To be clear, the objection is not that, if the desire-about-the-fiction view is right, you are somehow irrational for both wanting the show to go one way and wanting it not to. Rather, the objection is that you are of two minds about the fiction and, because of this, you are sure to be (in some respect) disappointed. [...] Our objection is that our engaging with Romeo and Juliet involved no such disappointment.

Their arguments are more likely to be described by the following steps: Having conflicting desires rationally implies that we are always disappointed or ambivalent. However, in engaging with fiction, we often have two conflicting desires without feeling disappointed or ambivalent; hence, we are irrational when we engage with fictions. It is false to say that the proponents of the idea of i-desires simply think that conflicting desires make consumers of fiction irrational.

The proponents of $\mathrm{i}$-desires judge that the desire + desire account implies that consumers of fictions are irrational, not because consumers violate the requirement of the 
consistency of desires but because they violate the rationality requirement for the functional roles of desires. Spaulding has considered four kinds of rationality requirements, including consistency, inference, justification, and possibility, but has not considered the functional roles of desires. In fact, Spaulding is inclined to consider only the theoretical rationality constraints on desires. She does not consider the practical rationality of desire because desires do not generate actions in engagement with fictions. Nevertheless, desires have two different functional roles: one is to cause actions; the other is to generate affective states. Although desires do not cause actions in engagement with fictions, they generate affective states. Thus, it is possible to understand rationality constraints on desires by considering their relation to our affective states.

One of the functional roles of desires is to generate disappointment when they are not satisfied. Nobody denies that satisfying a desire can make one feel pleasure. Conversely, if a desire is not satisfied, one would be disappointed. For example, I have a desire to go on holiday. If my desire is satisfied, I feel pleasure; but if I must go to work and my desire cannot be satisfied, I do not feel pleasure and am rather disappointed. Thus, if a person has two conflicting desires, she should always feel disappointed because there always exists one of her desires that cannot be satisfied. Suppose that I have a desire to smoke and also desire to give up. In this case, I would always be disappointed because if I smoked, my desire for my health cannot be satisfied; however, if I do not smoke, my desire to smoke cannot be satisfied. There is no state of affairs that can lead to both of my two desires being satisfied. The desire + desire account implies that in engaging with fictions, we have two conflicting desires. We have a desire that the fiction be such that the event $E$ occurs and also have a desire that the fiction be such that $E$ not occur. In this case, we are also always disappointed 
because there is no state of affairs that can lead to my conflicting desires being satisfied at the same time.

Desires can generate disappointment when they are not satisfied. Maybe we can imagine an individual whose desires do not have this functional role. When the individual's desire is not satisfied, she does not feel disappointed but rather pleasure or other positive emotions; or when her desire is satisfied, she does not feel any pleasure but negative emotions such as disappointment. We can imagine that one's desires have inverse roles or do not have the normal causal roles. Like David Lewis's "mad pain," one's desire may not occupy the typical functional role of desires (see Lewis 1980). However, although we can imagine such individuals, we are more likely to judge that they are bizarre, unusual, or irrational. $^{7}$ Thus, for a rational person, if her desire were not satisfied, then she would be disappointed. Given that a rational person has two conflicting desires, she would be disappointed all the time because there always exists one desire that is not satisfied. The rational response to the conflicting desires is disappointment. However, we are not always disappointed in engaging with fictions. We enjoy the fiction and often feel pleasure, happiness, or other positive emotions. Sometimes we may be disappointed when reading a novel or watching a film because what we want to happen does not happen. However, it is implausible to say that we are disappointed at all times. Thus, the desire + desire account makes us out to be irrational. ${ }^{8}$

7 Maybe someone does not think that an individual that has an inverse role of desires should be described as irrationality. They should be seen as unusual, bizarre or even physically impossible. But that does not rebut my argument for i-desires. I can claim that the desire + desire account implies that consumers of fiction are bizarre, but it is implausible to attribute to us "bizarre" at all times. Hence, the desire + desire account is not the best explanation.

8 It might be said that there is no single response to conflicting desires. A person is totally open to how she reacts to conflicting desires. Consider a person who both desires to smoke and to quit. Sometimes, she may feel triumphant when refraining from smoking; sometimes, she may feel pride; sometimes, this person may feel profound contentment. 
Summing up, the desire + desire account implies that in engaging with fictions, we have two conflicting desires. The conflicting desires rationally require that we are disappointed. However, we are not always disappointed in engaging with fictions; we enjoy the fiction and feel pleasure. Thus, we are irrational. Doggett and Egan do not need to consider whether conflicting desires themselves are irrational. Their arguments rely on the rationality requirement for the function of desires: if a rational person's desire were not satisfied, she would be disappointed. ${ }^{9}$

Reconsider the imagination + desire account. Doggett and Egan argue that this account faces the same problem as the desire + desire account since having a desire about a fictional event or character rationally requires having a corresponding desire about the content of the fiction. Spaulding claims that there is no rationality constraint on the inferential coherence of desires: one often has a desire that $p$ and recognizes that $p$ entails $q$,

Her affective responses are not limited to a disappointment or a single emotional response.

This proposal does not distinguish the following two questions: 1) What mental states could one have when one's desire is not satisfied? and 2) What states does the non-satisfaction of a desire typically cause? Question 1) is trivial. By virtue of one's background beliefs and desires, one can experience all kinds of emotional states when one's desire is not satisfied. Question 2) concerns the most typical consequence of a non-satisfaction of a desire. The nonsatisfaction of a desire is not a typical cause of the many emotional states that I feel. For instance, I feel pride, not only because one of my conflicting desires has not been satisfied, but because I desire to have self-control and I believe that it is not easy to quit smoking. Without the latter two, a person is not capable of feeling pride. When experiencing conflicting desires, one can have all kinds of emotions; however, most of these emotions are produced by one's background beliefs and desires rather than only by one's conflicting desires themselves. Here the opponent is focusing on question 1). However, the proponents of the desire + desire account certainly consider question 2): they want to consider what states the non-satisfaction of a desire typically causes and attempt to connect these states to our affective responses. If they turn to question 1), they must abandon the desire + desire account because question 2) implies that two conflicting desires alone cannot account for our affective responses. Therefore, the reviewer's proposal is not a defense of the desire + desire account.

9 I have not considered the emotion of ambivalence. But it seems that my argument can be applied into the ambivalence. The conflicting desires rationally require that we are ambivalent, but we are not ambivalent in engagement with fictions. Hence, we are irrational. 
but does not have a desire that $q$. However, the proponents of i-desires can avoid this objection by considering a rationality requirement that Spaulding has not considered. In other words, I argue that even if we admit that one were to have a desire about a fictional event without having a corresponding desire about the content of the fiction, the imagination + desire account still implies that consumers of fiction are irrational. What I shall consider is not a rationality requirement on the contents of desires, but rather a rational capacity to distinguish between fictions and facts .

A rational person can distinguish between fact and fiction. As rational beings, we know that what has happened in the fiction is isolated from the real world: a fictional character cannot exist in our actual world and that fictional events happen only in the fiction. We know that Holmes is a fictional detective and that he does not exist in the actual world. We also know that Romeo dies in fiction instead of in the real world; Sherlock Holmes does not live in the real world but rather in the London of the novel; Captain Haddock is Tintin's friend in comics, not in the real world. Perhaps it is not easy to make explicit our capacity to distinguish fiction and fact. However, nobody can deny that we are capable of distinguishing between fact and fiction. A person who confuses facts and fictions is often seen as irrational. It is irrational for a person to believe that if a woman is killed, then the criminal is Frankenstein's monster. Equally, it is irrational for a person to believe that he is Superman.

This capacity is involved in our thinking about the satisfaction conditions of desires triggered by a fiction: if a rational person has a desire that a fictional event occurs, she should know or recognize that the satisfaction condition of her desire includes reference to a 
fiction. ${ }^{10}$ When watching the tragedy Othello, we may desire that the Desdemona not die. If this desire were to be satisfied, it must be satisfied in the fictional world; we should recognize that it cannot be satisfied in the real world. Now suppose that in the actual world there is a woman named Desdemona who has a good life. In this case, our desire is not satisfied. Our desire that Desdemona not die is satisfied only when she has a good life in the play. Perhaps one does not have an explicit desire about the content of the work of fiction when one has a desire about a fictional event, but one should recognize that fictional events happen only in a fictional world. ${ }^{11}$

Spaulding argues that there is no inferential coherence requirement in relation to desires, and she gives a following example: I desire to run early in the morning, but I do not desire to get up early in the morning. I recognize that the former requires the latter. However, I can desire the former, but not the latter. In this case, it is implausible to attribute an irrationality to the subject. Yet, it seems that when one desires to run in the morning, one can recognize that this desire can be satisfied only when one get up early, although one does not desire to get up early. In daily life, we often have a desire to do $p$, and recognize that in

10 This requirement does not entail that a rational person does not have any genuine desire concerning fictional character. For example, a person may have a desire to one day see Santa Claus in action. I admit that a rational person may occasionally have such a desire or desires similar to this one. Her irrationality does not originate in the content of her desire but rather her thinking about the satisfaction of her desire. The type of rationality constraint I have considered in this section requires that if one is rational, then one ought to know that one's desire concerning fictional events cannot be satisfied in the real world. The best way to judge if a person is rational is by her thinking about the satisfaction condition of her desire. If she expressed a wish and knew that this desire cannot be satisfied in a real world because there does not exist Santa Claus, then she is rational; but, if she thought that this desire can be satisfied in a real world, she is irrational. Most people do not think that it is possible to find Santa Claus in the real world, although they may have a desire (or wish) to see him. Thus, most people are rational.

11 Real people can exist in fictional worlds, but fictional events are different from fictional characters. Fictional events can include fictional characters, but also real people. I do not believe that fictional events can happen in the real world. For example, if a story claims that Trump lost to Hillary Clinton, that would be a fictional event. If people think that it is true in the real world, then they are irrational. 
order to do $p$, we ought to do $q$, although we do not desire to do $q$. For example, I desire to get an $\mathrm{A}$ in a Latin class, and I know that I must work hard to receive a good result; however, I do not desire to work hard because of laziness. Equally, it seems that a reader also can desire that Anna not die and recognize that if it were true, it would only happen in the fiction, but not desire that she would survive in the fiction. Hence, the notion of the satisfaction conditions of desires is not a restatement of the criterion of inferential coherence that is rejected by Spaulding.

According to the imagination + desire account, we have a desire about fictional events that causes affective responses. If a rational person is capable of recognize that the satisfaction condition of her desire includes reference to a fiction, then her desire regarding fictional events would lead to a dilemma. Either we have a desire about fictional events and its condition of satisfaction does not include reference to fictions, or we have a desire about fictional events and its condition of satisfaction includes reference to fictions. Both of the two horns imply that consumers of fiction are irrational.

Suppose that we have a desire about fictional events and the condition of satisfaction does not include reference to the fiction. For example, we have a desire that Desdemona not die. Suppose that the desire is not satisfied when she has a good life in the play and that it is satisfied only when we find a woman named Desdemona in the real world. In this case, we are irrational, because we confuse fiction and facts. Desdemona is a fictional character, not a real woman. If we do not know that, we are sure to be irrational. We are irrational because we are inclined to think that fictional events happen in the real world.

Observe now the second horn of the dilemma: we have a desire concerning fictional events and its condition of satisfaction includes reference to a fiction. Suppose that $E$ refers 
to a tragic event that occurs in a work of fiction. In engaging with the work, a sympathetic reader would have a desire that $E$ not occur. The satisfaction condition of this desire should include reference to a fiction: the desire that $E$ not occur is satisfied only when $E$ does not occur in the fiction. Moreover, a reader also has another desire about the content of the fiction, because she knows that if a tragic event were to occur, the work would be more attractive; a tragic event is indispensable because it enhances the aesthetic values of a work. Thus, a reader also has a desire that the fiction be such that $E$ occurs. This desire is directed at the content of the fiction, not at the fictional event itself. Hence, its condition of satisfaction also includes reference to the fiction-it is satisfied only when E does occur in the fiction. Although the desire that $E$ not occur and the desire that the fiction to be such that $E$ occurs are directed at different objects (one is directed at a fictional event $E$; the other at the work of fiction itself), their conditions of satisfaction still conflict. There is no state of affairs that satisfies the two desires. The rational response to the two desires whose satisfaction conditions are in conflict still involves disappointment.

When two desires do not have conflicting content but have conflicting conditions of satisfaction, a rational response to them still involves disappointment. An example will clarify my argument. Suppose that in watching Romeo and Juliet, I have a desire that Juliet not die. The desire is satisfied only while she does not die in the play. Thus, the condition of satisfaction of my desire includes reference to the fiction. Moreover, I also have a desire about the content of the play: I desire that Juliet dies in the fiction because her death is indispensable for an excellent drama. Without Juliet's death, Romeo and Juliet would be a bad work. I have two desires: one is that Juliet not die; the other is that Juliet dies in the 
play. ${ }^{12}$ The two desires have conflicting conditions of satisfaction: it is impossible that Juliet both dies and does not die in the play. Thus, our rational response to the two desires should be a disappointment because one of the two desires will not be satisfied. However, we enjoy Romeo and Juliet as it is. We are not at all disappointed. Therefore, we are irrational.

$$
* * *
$$

To sum up. Spaulding argues that the imagination + desire and desire + desire accounts do not imply that consumers of fiction are irrational. I rebutted her arguments. The desire + desire account implies that consumers of fiction are irrational because they violate the rationality requirement for the functional roles of desires. The imagination + desire account implies that consumers of fiction are irrational because they violate either the rationality requirement for the distinction between fictions and facts or that for the functional roles of desires. Spaulding has not considered the two kinds of rational norms. I admit that my argument cannot decisively establish that the thesis of i-desires is the best account of our engagement with fiction. But, at least, my argument suffices to undermine Spaulding's objections.

12 My desire concerning the fictional character, Juliet, might trigger emotions that are different from those roused by my desire concerning the content of the fiction. For instance, my desire that Juliet not die can trigger pity for Juliet on my part. However, I still have two desires whose conditions of satisfaction are in conflict: one is that she not die, the other is that she dies in the play; hence, I always feel disappointed. It may be that this disappointment coexists with my pity for Juliet. However, my objection is that one's affective responses do not always involve such a disappointment. Therefore, this proposal cannot avoid the problems faced by the imagination + desire account. 
Reference

Currie, G. 2010. Tragedy. Analysis 70: 632-38.

Currie, G. and I. Ravenscroft. 2002. Recreative Minds: Imagination in Philosophy and Psychology. New York: Oxford University Press.

Doggett, T. and A. Egan. 2012. How We Feel about Terrible, Non-existent Mafiosi. Philosophy and Phenomenological Research 84: 277-306.

Funkhouser, E. and S. Spaulding. 2009. Imagination and Other Scripts. Philosophical Studies 143: 291-314.

Goldman, A. 2006. Simulating Minds: The Philosophy, Psychology, and Neuroscience of Mindreading. New York: Oxford University Press.

Kind, A. 2011. The Puzzle of Imaginative Desire, Australasian Journal of Philosophy 89: 421-39.

Lewis, D. 1980. Mad pain and Martian pain. In N. Block, ed., Readings in the Philosophy of Psychology. Cambridge: Harvard University Press.

Nichols, S. 2004a. Imagining and Believing: The Promise of a Single Code. The Journal of Aesthetics and Art Criticism 62: 129-139.

Nichols, S. 2004b. Review of Currie and Ravenscroft. Recreative Minds, Mind 113: 329-34.

Salis, F. 2016. The Problem of Satisfaction Conditions and the Dispensability of i-Desire. Erkenntnis 81: 105-118.

Spaulding, S. 2015. Imagination, Desire, and Rationality. The Journal of Philosophy 112: 457-476. 
Velleman, D. 2000. On the Aim of Belief. In The Possibility of Practical Reason. New York: Oxford University Press.

Walton, K. 1990. Mimesis as Make-Believe. Cambridge, MA: Harvard University Press.

Weinberg, J. and A. Meskin. 2006. Imagine that! In M. Kieran, ed., Contemporary Debates in Aesthetics and the Philosophy of Art, 222-35. Oxford: Blackwell. 